\title{
IMPLEMENTASI SISTEM PENGENDALI RUMAH PINTAR MENGGUNAKAN LARAVEL
}

\author{
Laila Khoirunnisa Nurul Imani ${ }^{1}$, Nanda Alicia ${ }^{2}$, Fahmizal $^{3}$, Unan Yusmaniar Oktiawati ${ }^{4}$ \\ 1,2,3,4 Departmen Teknik Elektro dan Informatika, Sekolah Vokasi, Universitas Gadjah Mada \\ laila99@mail.ugm.ac.id ${ }^{1}$, nandaalicia@mail.ugm.ac.id ${ }^{2}$, fahmizal@ugm.ac.id ${ }^{3}$,unan_yusmaniar@ugm.ac.id ${ }^{4}$
}

\begin{abstract}
The control of household electronic equipment can now be done remotely using a website, or better known as the smart home controller application to reduce waste of electricity usage. The electronic equipment that is controlled changes the lights and sockets. This electronic equipment controller website is made with the Laravel framework which uses the PHP 5.8 programming language which is closed, therefore a connection is made with the REST API that uses the Javascript programming language to bridge the communication between electronic equipment and the website. Delivery of data between the website and components requires a server and broker to broker data paths. Thus MQTT is needed as a means of exchanging data on the hardware side so it requires a gateway in the form of Node Js to connect PHP with MQTT. Test results are done by testing the speed of the lights using various internet connection media. The test results showed the fastest internet connection media, namely using a laptop connected to a WiFi internet network with an average speed of 0.691 seconds. The smart home controller website named Pantaw can be accessed using the UGM hotspot WiFi network.
\end{abstract}

Keywords: Website, smarthome, MQTT, Laravel, Node Js.

Intisari - Pengendali peralatan elektronik rumah tangga kini dapat dilakukan dari jarak jauh menggunakan website, atau lebih dikenal dengan istilah aplikasi pengendali rumah pintar guna mengurangi pemborosan pemakaian listrik. Adapun peralatan elektronik yang dikendalikan beruba lampu dan stopkontak. Website pengendali peralatan elektronik ini dibuat dengan framework Laravel yang menggunakan bahasa pemrograman PHP 5.8 yang bersifat tertutup, dimana kode PHP dijalankan di sisi server. Oleh karena itu, dibuat koneksi dengan REST API yang menggunakan bahasa pemrograman Javascript untuk menjembatani komunikasi antara peralatan elektronik dengan website. Pengiriman data antara website dan komponen memerlukan sebuah server dan broker untuk menjadi perantara jalur data. Dengan demikian MQTT diperlukan sebagai sarana pertukaran data di sisi hardware sehingga memerlukan sebuah gateway berupa Node Js untuk menghubungkan PHP dengan MQTT. Pengujian website dilakukan dengan menguji kecepatan nyala lampu menggunakan berbagai media koneksi internet. Hasil pengujian menunjukkan media koneksi internet yang tercepat yaitu dengan menggunakan laptop yang terkoneksi ke jaringan internet WiFi dengan kecepatan rata-rata 0.691 detik. Website pengendali rumah pintar yang diberi nama Pantaw ini dapat diakses menggunakan jaringan WiFi UGM hotspot.

Kata kunci: Website, rumah pintar, MQTT, Laravel, Node Js.

\section{PENDAHULUAN}

Dewasa ini seluruh sistem penunjang kebutuhan manusia dituntut untuk memiliki mobilitas yang semakin tinggi. Kebutuhan sistem penunjang dengan mobilitas yang tinggi tersebut digunakan untuk mempermudah kehidupan manusia sehingga manusia berlomba-lomba menciptakan inovasi-inovasi baru, terutama dalam bidang teknologi. Internet of things (IoT) di masa depan akan mengubah objek dunia nyata menjadi objek virtual yang cerdas[1]. Hal ini berarti setiap orang dan atau sesuatu memiliki locatable, addressable, dan dapat dibaca di internet[2]. Konsep IoT bertujuan membuat internet dapat lebih dimanfaatkan secara mendalam[3]. IoT dapat dianggap sebagai komponen infrastruktur jaringan global dari berbagai perangkat yang terhubung yang mengandalkan teknologi sensorik, komunikasi, jaringan, dan pemrosesan informasi[4]. IoT mengacu pada interkoneksi jaringan benda sehari-hari, yang dilengkapi dengan kecerdasan[5]. IoT tidak memiliki standar identififikasi[6]. Berkat manajemen daya yang semakin efifisien, komunikasi broadband, memori yang andal, dan kemajuan dalam teknologi mikroprosesor, telah dimungkinkan untuk mendigitalkan fungsi dan kapabilitas kunci dari produk pada zaman industri[7]. Internet saat ini tidak hanya diakses untuk kebutuhan komunikasi, namun bisa juga digunakan sebagai sarana pengendali jarak jauh seperti pada peralatan elektronik di kantor maupun di rumah. Konsep tersebut lebih dikenal dengan smarthome atau rumah pintar.
Konsep smarthome memainkan peran penting dalam perencanaan model perumahan untuk masa depan[8]. Banyak orang berpendapat bahwa dunia itu sendiri akan dapat dilengkapi indra dan aktuasi dan menciptakan apa yang disebut sebagai dunia yang cerdas[9]. Konsep rumah pintar diharapkan dapat memberikan kenyamanan, keamanan serta efisien bagi pengguna. Konsep ini memudahkan seseorang untuk mengendalikan peralatan elektronik yang ada di rumahnya dari jarak jauh[10]. Kontrol peralatan rumah seperti pendingin udara, pendingin, mesin cuci, dan lain-lain akan memungkinkan pengelolaan rumah dan energi yang lebih baik[11]. Peralatan elektronik yang dikendalikan pada penelitian ini berupa lampu dan stopkontak. Lampu merupakan alat penerang di tempat yang gelap maupun pada malam hari. Lampu sendiri sering digunakan oleh masyarakat sehingga seringkali penggunaannya berlebihan dan menyebabkan pemborosan penggunaan listrik. Salah satu solusi untuk permasalahan tersebut adalah pemilik rumah dapat mengendalikan pemakaian peralatan listrik dari jarak jauh melalui web. Pengendalian berbasis web diharapkan mampu memudahkan pemilik rumah karena dapat dilakukan baik melalui ponsel maupun perangkat lainnya yang terhubung dengan internet dimana saja dan kapan saja. Selain itu dengan akses pengendalian yang mudah diharapkan pengguna dapat memakai peralatannya secara bijak dan untuk menghemat pemakaian listrik. Keseluruhan sistem yang dikembangkan dalam penelitian "Implementasi Sistem Pengendali Rumah Pintar 
Menggunakan Laravel" diharapkan dapat memudahkan pengguna untuk mengendalikan peralatan rumah tangga lebih efisien.

\section{METODE}

\subsection{Gambaran Umum Alat}

Implementasi website berbasis Laravel adalah sebagai alat kontrol elektronik berupa empat buah lampu dan juga empat buah stopkontak yang digunakan untuk berbagai macam alat elektronik seperti kipas angin, lampu, dan lainlain. Gambar 1.a menunjukkan gambaran umum bentuk hardware yang dikontrol menggunakan web berbasis Laravel dan Gambar 1.b menunjukkan bentuk hardware sesungguhnya.

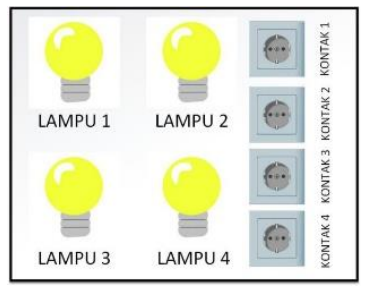

(a)

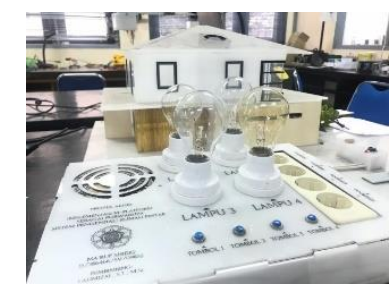

(b)
Gambar 1. (a) Gambaran rancangan hardware (b) Bentuk asli hardware

\subsection{Skema Perancangan Elektronis}

Desain elektronis dibuat dengan menghubungkan empat komponen utama yaitu modul relay, Arduino Mega, pada ethernet shield protocol (ESP), lampu, dan stopkontak. Pin pada Arduino Mega yang digunakan adalah pin digital 53, $51,49,47$ yang tehubung ke relay untuk mengatur lampu dan pin 45, 43, 41, 39 yang terhubung ke relay untuk mengatur stopkontak. Pin 'Tx' ESP terhubung ke pin 'Rx' pada Arduino Mega, sedangkan pin 'Rx'pada ESP terhubung ke pin 'Tx' pada Arduino Mega. Berikut detail perancangan elektronis yang terlihat pada Gambar 2.

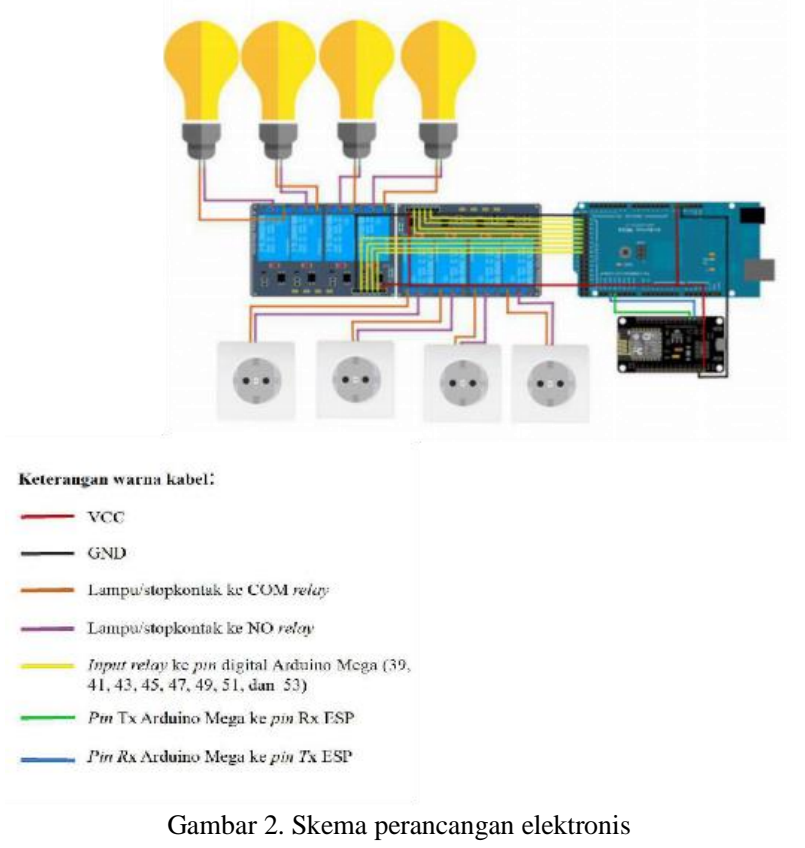

\subsection{Sistem Komunikasi Data}

Proses pertukaran data dimulai dari hardware yang terhubung ke MQTT broker, kemudian baru data dikirim ke website berbasis Laravel. Laravel menggunakan bahasa pemograman PHP yang sifatnya tertutup atau kodenya dijalankan di sisi server[12], sehingga dibuat sebuah representational state transfer (REST API) untuk menghubungkan MQTT broker dengan website. Data yang sudah sampai di web, kemudian dimasukkan ke dalam database. Sistem alur komunikasi data ini juga dapat berjalan secara dua arah atau bolak-balik.

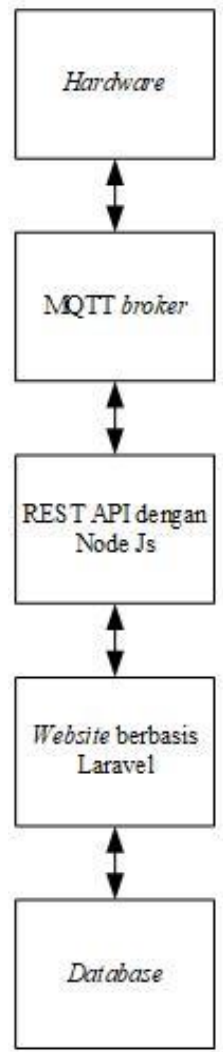

Gambar 3. Sistem komunikasi data

\subsection{Perancangan Komunikasi MQTT}

Seperti pada Gambar 3, sebagai media pertukaran data digunakan sebuah MQTT. Pada MQTT struktur pengiriman data menggunakan topik untuk tempat data. Pada tiap-tiap topik akan menjadi acuan tiap data dikirimkan. Setiap data akan ditempatkan atau dikirimkan pada topik-topik yang berbeda. Berikut merupakan pembagian topik yang dijelaskan pada Tabel 1.

Tabel 1 Pembagian topik pada MQTT

\begin{tabular}{ccc}
\hline Item & Topik & Pesan \\
\hline Lampu 1 & LED/1 & $0=$ OFF $; 1=$ ON \\
Lampu 2 & LED/2 & $0=$ OFF $; 1=$ ON \\
Lampu 3 & LED/3 & $0=$ OFF $; 1=$ ON \\
Lampu 4 & LED/4 & $0=$ OFF $; 1=$ ON \\
Kontak 1 & KONTAK $/ 1$ & $0=$ OFF $; 1=$ ON \\
Kontak 2 & KONTAK/2 & $0=$ OFF $; 1=$ ON \\
Kontak 3 & KONTAK/3 & $0=$ OFF $; 1=$ ON \\
Kontak 4 & KONTAK/4 & $0=$ OFF $; 1=$ ON \\
\hline
\end{tabular}




\subsection{Alur Diagram Aplikasi}

Gambar 4 menjelaskan alur diagram aplikasi dimulai saat pengguna melakukan inisialisasi untuk menyalakan atau mematikan peralatan elektronik. Terdapat delapan tombol yang terdiri dari empat tombol untuk lampu dan empat tombol untuk stopkontak. Pengguna dapat memilih tombol mana yang akan difungsikan. Jika pengguna menekan tombol on atau off, maka website akan mengirim perintah ke Arduino Mega dan akan dilanjutkan menuju alat yang dituju, baik itu lampu maupun stopkontak. Adapun ketika pengguna melakukan logout, maka website akan diarahkan menuju ke halaman utama.

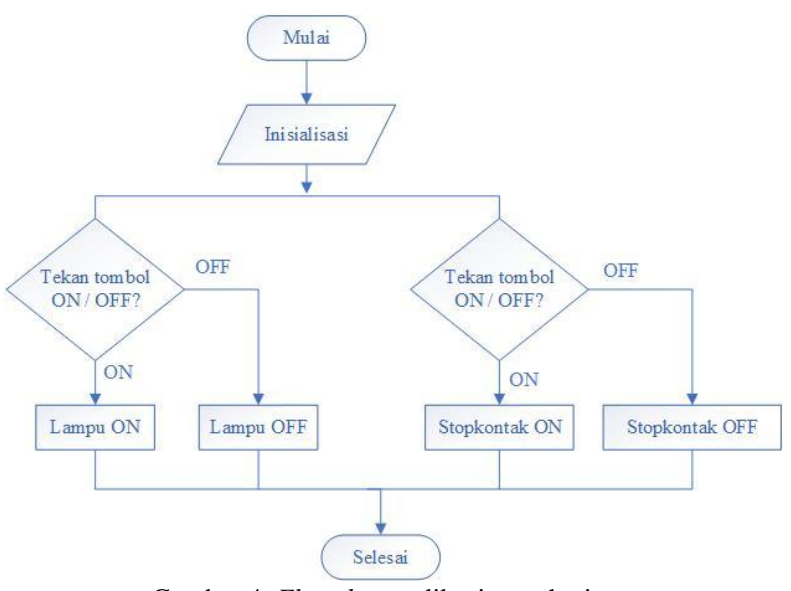

Gambar 4. Flowchart aplikasi rumah pintar

2.6 Alur Diagram Sistem Login

Gambar 5 menjelaskan alur diagram sistem login. Pengguna memulai dengan mengakses situs website lalu masuk ke halaman login dan memasukkan user id dan password yang telah didapat. Jika user id dan password yang dimasukkan benar, maka pengguna akan diarahkan menuju dashboard utama, namun jika gagal maka secara otomatis pengguna akan diarahkan lagi ke halaman login untuk memasukkan kembali user id dan password yang benar.

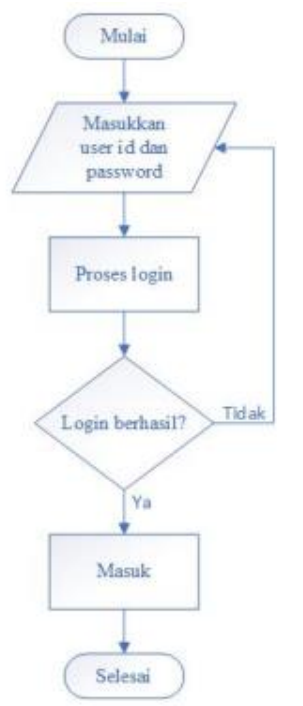

Gambar 5. Flowchart sistem login

\subsection{Perancangan Interface}

Perancangan interface website meliputi perancangan pada halaman-halaman yang terdapat pada website, diantaranya yaitu halaman utama, halaman login, dan halaman dashboard. Halaman utama ialah halaman yang tertampil ketika pengguna mengakses ke alamat website. Halaman login ialah halaman untuk pengguna masuk ke dalam akunnya masing-masing untuk dapat mengakses sistem pengendalian pada rumah pintar. Halaman dashboard yaitu halaman yang memuat tombol untuk mengendalikan peralatan elektronik yang ada di rumah pengguna. Terdapat delapan tombol atau saklar pada halaman ini yang terdiri dari empat saklar lampu dan empat saklar stopkontak. Gambar 6 menunjukkan tampilan halaman dashboard yang terdapat (1) sidebar menu pada dashboard, (2) nama peralatan yang dimiliki pengguna, dan (3) tombol switch on/off.
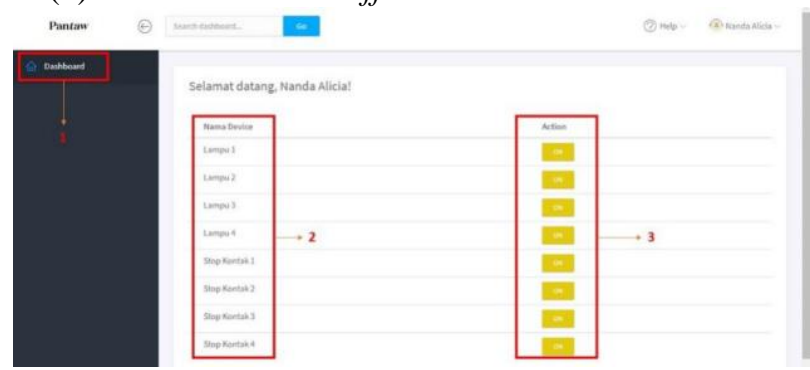

Gambar 6. Interface halaman utama

Halaman ini hanya dapat diakses oleh pengguna yang sudah terdaftar, sehingga data masing-masing pengguna sangat terjamin keamanannya.

\section{HASIL DAN PEMBAHASAN}

Website pada penelitian ini berperan sebagai remote untuk mengendalikan peralatan elektronik di rumah tangga. Adapun bahasa pemrograman yang digunakan pada Laravel ialah hypertext prepocessor (PHP). Sementara bahasa pemrograman PHP itu sendiri bersifat tertutup atau dijalankan di sisi server[12], maka dari itu dibuatlah koneksi dengan REST API untuk menjembatani komunikasi antara peralatan elektronik dengan website. REST API menggunakan bahasa pemrograman berupa Javasript. Pengiriman data antara website dan komponen memerlukan sebuah server dan broker untuk menjadi perantara jalur data. Server yang digunakan ialah server Departemen Teknik Elektro dan Informatika Sekolah Vokasi UGM dengan alamat IP 10.33.109.37. Adapun broker yang digunakan sebagai media pertukaran data ialah MQTT yang berfungsi mengirim dan menerima pesan antara hardware dengan website.

\subsection{Implementasi PHP pada Perancangan Antarmuka}

Website sistem pengendali rumah pintar ini diberi nama Pantaw. Pemilihan platform website sebagai basis aplikasi ini dimaksudkan agar pengguna bisa mengaksesnya melalui smartphone maupun desktop. Tampilan antarmuka website pada Laravel terdapat dalam folder "views/" yang digunakan untuk menyimpan file-file PHP untuk keperluan tampilan (frontend) aplikasi. Setelah pengguna login dengan akun Pantaw, pengguna akan terarahkan menuju halaman dashboard yang dipangggil oleh routing lalu diarahkan menuju ke alamat "/dashboard". Routing digunakan untuk menangani request yang diberikan ke dalam website. Setiap ada request ke alamat tertentu, routing akan mengeksekusi sebelum akhinya menampilkan respon. Route "/dashboard" hanya dapat diakses oleh 
pengguna yang memiliki akun Pantaw. Hal itu dikarenakan pada route-route tertentu telah dipasang middleware yang mana dalam konteks Laravel merupakan class khusus yang berperan sebagai penengah antara request tertentu untuk menuju ke controller. Dalam hal ini penggunaan middleware bertujuan untuk memverifikasi status login setiap pengguna untuk menuju route "/dashboard".

3.2 Implementasi PHP pada Perancangan Tabel Basis Data

Konsep pada website pengendali rumah pintar ini adalah pengguna dapat mengendalikan peralatan elektronik sesuai dengan yang dimilikinya. Dengan demikian, digunakan dua unsur pengendalian yairu pengguna dan peralatan yang dikontrol, sehingga dibuat dua tabel pada basis data untuk menyimpan informasi tersebut, yaitu tabel users dan devices. Maka dari itu perlu dibuat relasi antara kedua tabel tersebut agar bisa terkoneksi satu sama lain berupa relasi one to many yang merupakan relasi dimana suatu data pada tabel dapat memiliki banyak data dari tabel lain dan begitu pula banyak data dari tabel dimiliki oleh satu data dari sebuah tabel[13]. Dalam hal ini, terdapat pada hubungan antara tabel user dan tabel device pada basis data. Gambar 7 menunjukkan skema relasi one to many antara tabel device dan user pada basis data.
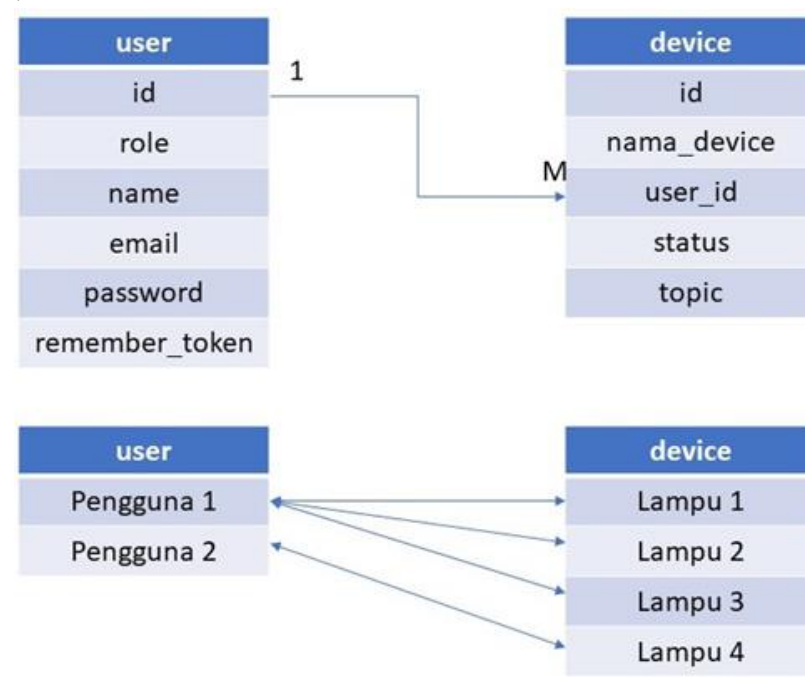

Gambar 7. One to many relationship

3.3 Implementasi PHP pada Sistem Kendali secara Keseluruhan

Halaman dashboard terdiri dari data-data perangkat yang dimiliki oleh pengguna. Perangkat elektronik itu sendiri terdiri dari lampu dan stopkontak yang masing-masing berjumlah empat buah. Terdapat pushbutton untuk menyalakan atau mematikan perangkat. Ketika pengguna menekan pushbutton, ia akan mengirim request ke route state pada file "web.php". Jika pushbutton dalam kondisi ON ditekan maka ia akan request ke route dengan state 'off' dan jika pushbutton dalam kondisi $O F F$ ditekan makai a akan request ke route dengan state 'on'. Route state akan mengarahkan menuju DeviceController.php dimana pada controller tersebut terdapat fungsi state on dan off. Selain kondisi perangkat tersimpan ke basis data, kondisi tersebut juga akan terpublikaskan ke MQTT broker lewat perantara DashboardController.php yang mengirim alamat endpoint menuju gateway untuk kemudian dapat terhubung ke hardware. Hasil pengujian ini dapat pula dilihat pada [14].

\subsection{Perancangan MQTT}

Penggunaan MQTT dimaksudkan untuk perantara pengiriman data. MQTT dipilih karena dengan penggunaannya sebagai media perantara pengiriman data, menjadikan hardware menjadi hemat daya. Pembuatan website ini ditujukan untuk keperluan mengontrol peralatan elektronik yang ada di dalam beberapa ruangan. Pengontrolan dari sisi hardware dilakukan dengan menggunakan Arduino Mega. Selain dengan Arduino Mega, pada sisi hardware juga terpasang ESP yang berfungsi sebagai penghubung hardware ke jaringan internet. Pengujian MQTT dilakukan dengan menggunakan extensions MQTT Lens.

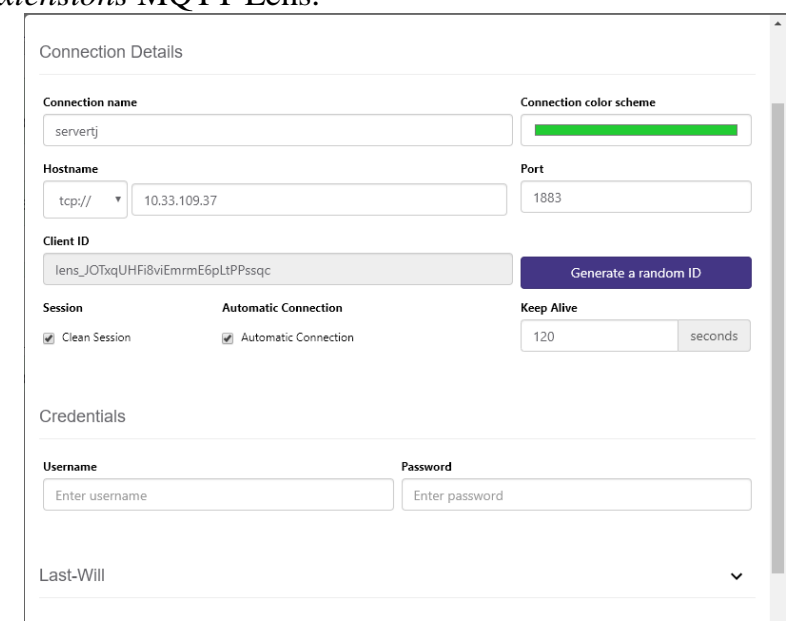

Gambar 8. Detail pengaturan pada MQTT Lens

3.5 Pembuatan Gateway dengan Node Js

REST API merupakan jembatan yang menghubungkan website berbasis Laravel dengan MQTT. REST API digunakan karena pada Laravel bahasa yang digunakan adalah bahasa pemograman PHP, sehingga sifatnya adalah tertutup. Oleh karena itu untuk menghubungkan website dengan hal eksternal lainnya digunakanlah REST API. Berikut merupakan program REST API dari sistem ini:

Program REST API tersebut dijalankan pada sisi server, sehingga tidak perlu dilakukan running program setiap akan menggunakannya. Pada REST API dibuat endpoint untuk mengirim setiap data yang akan dilewatkan di ke hardware dari sisi website. Nantinya REST API akan meneruskan topik beserta message atau pesan ke alamat yang sesuai dari Laravel menuju MQTT.

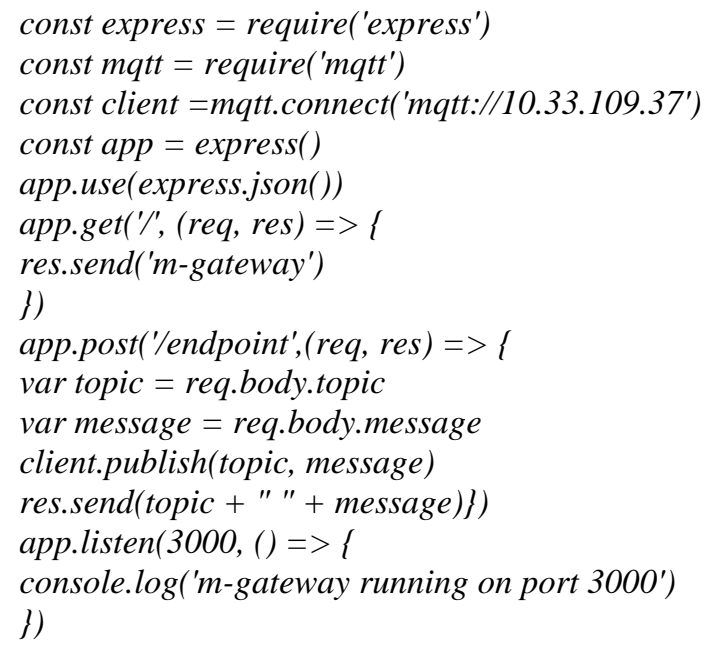




\subsection{Pengujian Koneksi PHP ke MQTT}

Jaringan internet digunakan sebagai media pengiriman data melalui server dari Laravel ke MQTT dan hardware. Kecepatan kontrol nyala lampu dengan melalui internet diuji dengan menggunakan tiga cara yang berbeda. Berikut hasil dari pengujian kecepatan nyala lampu ditunjukkan pada Tabel 2.

\begin{tabular}{cccc}
\multicolumn{4}{c}{ Tabel 2 Pengujian kecepatan nyala lampu } \\
\hline & $\begin{array}{c}\text { Smartphone } \\
\text { terkoneksi } \\
\text { WiFi }\end{array}$ & $\begin{array}{c}\text { Laptop } \\
\text { terkoneksi } \\
\text { WiFi }\end{array}$ & $\begin{array}{c}\text { Laptop } \\
\text { terkoneksi } \\
\text { kabel LAN }\end{array}$ \\
\hline $\begin{array}{c}\text { Pengujian } \\
\text { ke-n }\end{array}$ & \multicolumn{3}{c}{ Waktu (detik) } \\
\hline 1 & 0.95 & 0.88 & 1.62 \\
2 & 0.92 & 0.60 & 0.98 \\
3 & 1.23 & 0.40 & 0.79 \\
4 & 0.79 & 0.58 & 0.73 \\
5 & 0.91 & 0.75 & 1.03 \\
6 & 0.76 & 0.66 & 0.72 \\
7 & 0.81 & 0.86 & 1.25 \\
8 & 0.77 & 0.70 & 0.96 \\
9 & 0.76 & 0.76 & 0.86 \\
10 & 0.75 & 0.72 & 1.38 \\
\hline Rata-rata & 0.8565 & 0.691 & 1.032 \\
\hline
\end{tabular}

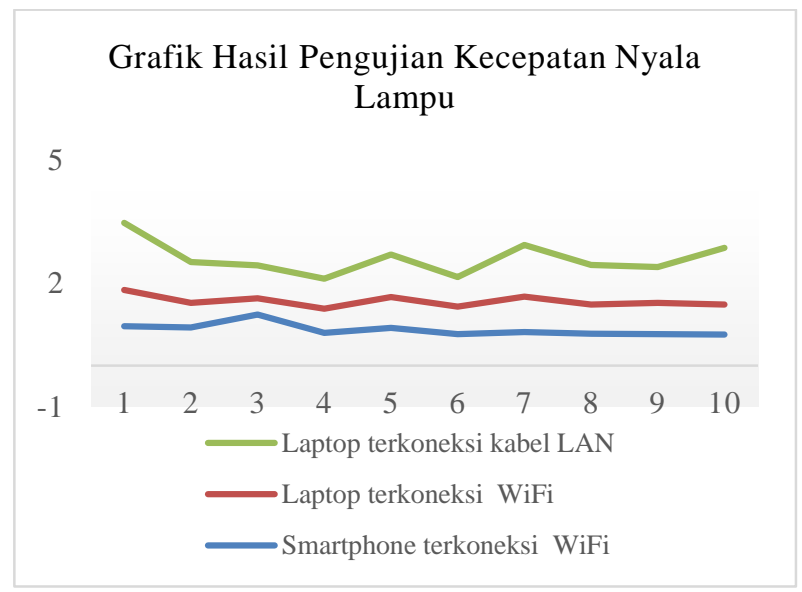

Gambar 9. Grafik hasil pengujian kecepatan nyala lampu

Berdasarkan hasil pengujian, dapat diketahui bahwa respon tercepat untuk menyalakan lampu adalah dengan menggunakan laptop yang terhubung ke jaringan internet melalui WiFi.

\section{KESIMPULAN}

Berdasarkan hasil pembahasan mengenai "Implementasi Sistem Pengendali Rumah Pintar Menggunakan Laravel" telah dilakukan pengujian kecepatan nyala lampu menggunakan media koneksi internet yang berbeda-beda. Pengujian kecepatan nyala lampu yang tercepat yaitu dengan menggunakan laptop yang terkoneksi ke jaringan internet WiFi dengan kecepatan rata-rata 0.691 detik. Sementara pengujian dengan smartphone terkoneksi ke jaringan internet WiFi memiliki kecepatan rata-rata 0.8565 detik dan pengujian dengan laptop yang terkoneksi melalui kabel LAN memiliki kecepatan rata-rata 1.032 detik. Relasi one to many antara perangkat dengan user menyebabkan keterbatasan akses untuk mengendalikan perangkat elektronik karena satu perangkat hanya bisa dimiliki atau dikendalikan oleh satu pengguna.

\section{DAFTAR PUSTAKA}

[1] S. Madakam, R. Ramaswamy, and S. Tripathi, "Internet of Things (IoT): A Literature Review,” J. Comput. Commun., vol. 03, no. 05, pp. 164-173, 2015.

[2] J. Zheng, D. Simplot-Ryl, C. Bisdikian, and H. T. Mouftah, "The internet of things," IEEE Commun. Mag., vol. 49, no. 11, pp. 30-31, 2011.

[3] A. Zanella, N. Bui, A. Castellani, L. Vangelista, and M. Zorzi, "Internet of things for smart cities," IEEE Internet Things $J$., vol. 1, no. 1, pp. 22-32, 2014.

[4] L. Da Xu, W. He, and S. Li, "Internet of things in industries: A survey," IEEE Trans. Ind. Informatics, vol. 10, no. 4, pp. 2233 2243, 2014.

[5] O. León, J. Hernández-Serrano, and M. Soriano, "Securing cognitive radio networks," Int. J. Commun. Syst., vol. 23, no. 5 , pp. 633-652, 2010.

[6] L. Tan and N. Wang, "Future Internet: The Internet of Things," ICACTE 2010 - 2010 3rd Int. Conf. Adv. Comput. Theory Eng. Proc., vol. 5, pp. 376-380, 2010.

[7] F. Wortmann and K. Flüchter, "Internet of Things: Technology and Value Added," Bus. Inf. Syst. Eng., vol. 57, no. 3, pp. $221-$ 224, 2015.

[8] L. Jiang, D. Y. Liu, and B. Yang, "Smart home research," Proc. 2004 Int. Conf. Mach. Learn. Cybern., vol. 2, no. August, pp. 659-663, 2004

[9] J. A. Stankovic, "Research directions for the internet of things," IEEE Internet Things J., vol. 1, no. 1, pp. 3-9, 2014.

[10] C. Hasiholan, R. Primananda, and K. Amron, "Implementasi Konsep Internet of Things pada Sistem Monitoring Banjir menggunakan Protokol MQTT," J. Pengemb. Teknol. Inf. dan Ilmu Komput. Univ. Brawijaya, vol. 2, no. 12, pp. 6128-6135, 2018.

[11] J. Gubbi, R. Buyya, S. Marusic, and M. Palaniswami, "Internet of Things (IoT): A vision, architectural elements, and future directions," Futur. Gener. Comput. Syst., vol. 29, no. 7, pp. 1645-1660, 2013.

[12] A. Aulbach, A. Zmievski, and E. Schmid, "PHP Manual," pp. $1-1520,2003$.

[13] G. Triyono, "Pertimbangan Melakukan Denormalisasi Pada Model Basis Data Relasi," J. Telemat. MKOM, vol. 3, no. 2, pp. $19-25,2011$.

[14] Fahmizal (2020) Video Implementasi Sistem Pengendali Rumah Pintar menggunakan Website berbasis Laravel, [Online] https://youtu.be/bHXBHCZdfGg, tanggal akses: 29-Jan2020. 